\title{
ACCLIMATIZATION OF THE ENDANGERED MEXICAN EPIPHYTIC ORCHID, LAELIA SPECIOSA (H.B.K.) SCHLTR.
}

\section{MARTHA MIREYA ORTEGA-LOEZA ${ }^{1}$, RAFAEL SALGADO-GARCIGLIA², CARLOS GÓMEZ-ALONSO ${ }^{3}$, and IRENE ÁVILA-DÍAZ,**}

\author{
${ }^{1}$ Instituto Tecnológico Superior de Coalcoman. Coalcoman de Vezquez Pallares, Centro, Álvaro Obregón 580, C.P. 60840 \\ Coalcomán Michoacán, México \\ ${ }^{2}$ Instituto de Investigaciones Químico-Biológicas de la Universidad Michoacana de San Nicolás de Hidalgo, Edificio B-3. \\ Ciudad Universitaria, C.P. 58040 Morelia, Michoacán, México \\ ${ }^{3}$ Centro de Investigación Biomédica de Michoacán IMSS, Camino de las Arboledas No. 300. Fracc. Exhda. De San José \\ de la Huerta. C.P. 58341 Morelia, Michoacán, México \\ ${ }^{4}$ Facultad de Biología de la Universidad Michoacana de San Nicolás de Hidalgo. Edif. R planta baja. Ciudad Universitaria, \\ C.P. 58040 Morelia, Michoacán, México \\ *Correponding author: iaviladiaz5@gmail.com; Tel. and Fax: 0524433167412
}

\section{ABSTRACT}

In vitro propagation could be an alternative for the conservation of the endemic and endangered Mexican epiphytic orchid Laelia speciosa (H.B.K.) Schltr. The goal of this study was to develop a protocol that would enhance acclimatization of in vitro - derived $L$. speciosa plantlets - a critical stage in propagation and subsequent conservation. Observations of stomata opening during ex vitro acclimatization, and the time of in vitro culture $(0,5,10,15,20,25,30$ days) in greenhouse conditions (pre-acclimatization), on the survival and development of seedlings during the ex vitro acclimatization were carried out. In addition, the effect of different levels of nutrients $(100 \%, 75 \%$, $50 \%, 25 \%$ and $0 \%$-strength salts) and sucrose $\left(0,10,20,30,40 \mathrm{~g} \mathrm{l}^{-1}\right)$ in the Murashige and Skoog medium (MS) on the same parameters were measured. Plantlets incubated 20 days in greenhouse conditions before ex vitro acclimatization also displayed the best growth with a survival rate of $97.5 \%$, related with high stomata opening. Plantlets on MS containing 100\%-strength salts (with 20 days of pre-acclimatization, $40 \mathrm{~g} \mathrm{l}^{-1}$ sucrose) had the highest rate (97.5-100\%) of survival and vigor when acclimatized. By improving micropropagation through acclimatization, the sustainable management of $L$. speciosa now more likely, benefitting the conservation of this endangered species.

Keywords: acclimatization, in vitro, micropropagation, orchid

\section{Introduction}

The endemic Mexican epiphytic orchid Laelia specio$s a$ (H.B.K.) Schltr., is threatened with extinction due to overcollecting for ornamental, cultural, and/or commercial purposes. The destruction of its habitat has also led to drastically diminished existing populations. A multidisciplinary project of study on L. speciosa, includes biological research and work with local people in communities to reach a sustainable management. An alternative for sustainable management of $L$. speciosa includes in vitro propagation. Such protocols have been developed for the establishment and in vitro propagation of this species through seed (Ávila-Díaz et al. 2009) and micropropagation from callus and shoot regeneration (Sarabia et al. 2010). These studies reported a survival as high as $70 \%$ to $77.5 \%$ in plantlets and seedlings of $5 \mathrm{~cm}$ in length after 30 days of being transplanted using tezontle (small red basaltic-volcanic-rocks) and oak bark 1:1 as substrate. However, plantlets survival diminished over time during cultivation with a $30 \%$ survival rate after 90 days.

Similarly, many other species of horticultural plants are easily micropropagated in vitro but exhibit poor acclimatization and subsequent survival ex vitro (Debergh and Zimmerman 1991). In vitro plantlets produced under high humidity conditions and transferred ex vitro to the soil are usually very susceptible to desiccation (Wetzstein and Sommer 1983). Typically, low light intensities in vitro result in the production of leaves that resemble shade or hydrophytic leaves ex vitro (Lee et al. 1988). These leaves often have little epicuticular and cuticular wax formation (Grout 1975) and malfunctioning stomata (Brainerd and Fuchigami 1981). Some medium components, such as sucrose, also affect the morphology of plantlets.

Acclimatization is also a critical stage in orchid micropropagation, because there are high percentages of damaged and lost plants whenever they are transferred to ex vitro conditions (Torres et al. 2006; Deb and Imchen 2010). Many different approaches toward efficient ex vitro establishment of the in vitro raised orchids have been employed, such as using different in vitro culture media, alternate substratum (Deb and Imchen 2010), hydroponic systems (Lopes da Silva 2006) and concentration of agar and sucrose in the medium; since it is said to have an effect on plant development on ex situ conditions (Deb and Imchen 2010).

The usage of different potting mixtures on the transplantation stage of orchid acclimatization has been investigated to increase the survival of some orchids like Euchile mariae (Suárez-Quijada et al. 2007), Laelia speciosa (Ávila-Díaz et al. 2009), Cattleya maxima x nobilior (Díaz et al. 2010), Cattleya harrisoniana and Laelia pur- 
purata (Seidel-Junior and Augusto-Venturieri 2011). For the genus Phalaenopsis and Cattleya (Diaz et al. 2010), as well as for Laelia speciosa (Ávila-Díaz et al. 2009), size of seedlings has been researched for acclimatization purposes, in the same manner, using diverse plant growth regulators during acclimatization has been useful in increasing root and vegetative development, such is the case of the application of $200 \mathrm{mg} \mathrm{l}^{-1}$ of NAA sprayed on seedlings of Oncidium baueri (Sorace et al. 2007).

In the current study, we have established an efficient system of acclimatization of seedlings propagated in $v i$ tro of L. speciosa, determining the effect of difference in time of exposure in a greenhouse of in vitro cultures of L. speciosa seedlings (pre-acclimatization) on growth and stomatal dynamics during the phase of acclimatization. We also analized the effect of different concentrations of nutrients and sucrose on MS basal medium during in vitro culture, to analize the growth and survival of L. speciosa seedlings in the acclimatization.

\section{Methods}

\section{Time of in vitro culture in greenhouse conditions (pre-acclimatization)}

\section{Effect of pre-acclimatization on plant growth}

After 10 months of in vitro culture, 210 seedlings of Laelia speciosa (H.B.K.) Schltr., were used to investigate the effect of time of in vitro culture in greenhouse conditions (pre-acclimatization) on the survival and development of seedlings and stomata opening during the ex vitro acclimatization. These seedlings were grown previously on MS medium (Murashige and Skoog 1962) without plant growth regulators, with $30 \mathrm{~g} / \mathrm{l}$ of sucrose, pH 5.7 and under light conditions (suggested by ÁvilaDíaz et al. 2009), proceeding from a mature capsule.

Seven study groups were carried out with different treatments of pre-acclimatization as follows: $0,5,10,15$, 20,25 , and 30 days. Each study group consisted of 10 (120 ml) glass jars (with 3 seedlings of ca. $5 \mathrm{~cm}$ in length). Each glass jar contained $25 \mathrm{ml}$ of MS which was covered with clear plastic caps.

After the permanence of the in vitro cultures in greenhouse conditions, each plant was washed carefully with distilled water to eliminate agar residue, and was then
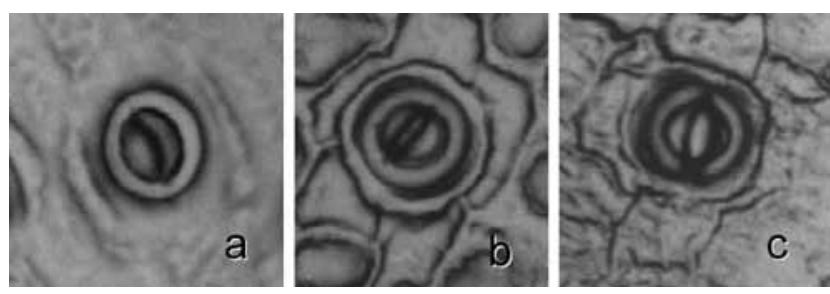

Fig. 1 Categories of stomata opening: 1, closed stomata (a); 2, partially open stomata (b) and 3, open stomata (c). placed on absorbent paper to determine the following measurements: length and width of the new leaf, length of the new pseudobulb, length and width of the roots of this pseudobulb and vigor was recorded. The measured parts were marked with a small indelible point to identify and measure the same structures subsequently. Seedlings were transplanted into individual plastic pots with tezontle-oak bark; 1 : 1 as was suggested by Ávila-Díaz et al. in 2009. The fungicide thiabendazole (Tecto 60) was applied in a concentration of $1 \mathrm{~g} \mathrm{l}^{-1}$, to prevent any possible infection by pathogenic fungi.

Seedlings were maintained in acclimatization chambers with clear plastic bags. Bags were gradually opened every 2 days until they were completely removed after 30 days. After 7 months, the previously mentioned parameters and survival were also recorded.

Data were analyzed using one-way analysis of variance and Tukey Post Hoc test for the difference between final and initial observations for each parameter, assisted by SPSS 18.0 program for Windows (SPSS Inc. Chicago, IL, USA).

\section{Effect of pre-acclimatization on stomata opening}

Stomata opening during ex vitro acclimatization was evaluated on 10 randomly-selected seedlings for each pre-acclimatization treatment. Impressions on the abaxial side of new leaves were made with a dental mold pulp exactodent, at 5:00 a.m., 9:00 a.m., and 2:00 p.m. once a month (June to September), once the 30-day of pre-acclimatization seedlings were transplanted, during 4 months. The exactodent mold was covered with transparent nail polish, and once it dried, it was removed and observed under light microscopy to assess stomata opening on 10 stomata on each seedling. Categories were established based on stomata opening, assigning 1 to closed stomata, 2 to stomata partially open and 3 to open stomata (Fig. 1).

Data were analyzed in the same manner described previously.

\section{Effect of different levels of MS nutrients previous to acclimatization}

Seedlings proceeding from seeds of a mature capsule, grown in vitro as previously described, were subcultured in MS medium with different levels of nutrients (100\%, $75 \%, 50 \%, 25 \%$, and $0 \%$-strength salts). Each study group consisted of $10(120 \mathrm{ml})$ glass jars, each one containing 4 seedlings. After 60 days, seedlings were placed in greenhouse conditions for 20 more days and transplanted into individual plastic pots which were maintained in acclimatization chambers, uncovering gradually as described above. Seedling survival, length and width of the new leaf, length of the new pseudobulb, length and width of the largest root of this pseudobulb, and vigor were recorded during transplant, and after 5 months.

Data were analyzed in the same manner described previously. 


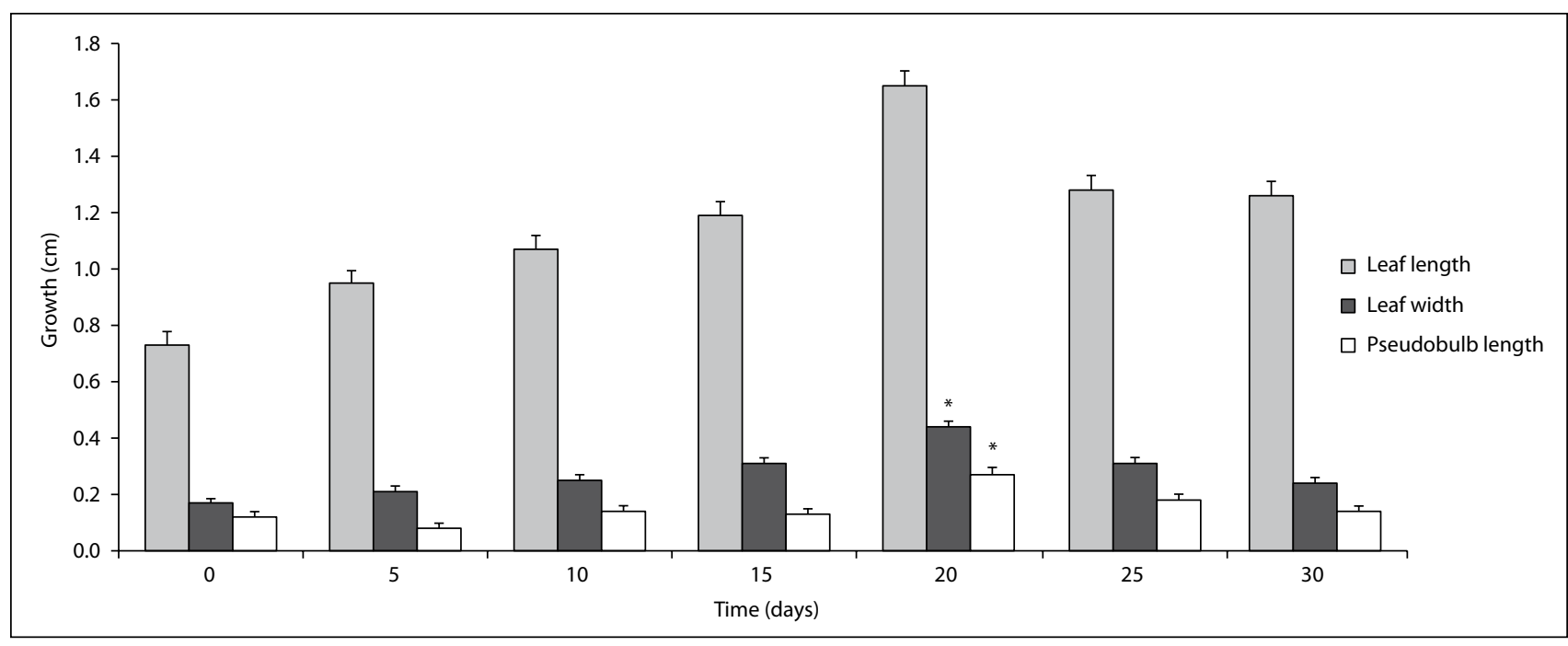

Fig. 2 Effect of the pre-acclimatization time on Laelia speciosa growth, ${ }^{*}$ means significant differences at $P>0.05$.

\section{Effect of sucrose concentration in the MS medium previous to acclimatization}

We studied the effect of different sucrose concentration $\left(0,10,20,30,40 \mathrm{~g} \mathrm{l}^{-1}\right)$ in the MS during 60 days of in vitro culture on the same parameters described before during acclimatization.

Seedlings used in this experiment were of the same source than those of the previous experiment. In addition, 40 similar seedlings for each study group were used, $10(120 \mathrm{ml})$ glass jars, each one containing 4 seedlings. Before transplant, seedlings in vitro, were placed in greenhouse conditions for 20 more days and were transplanted and acclimatizated, as in previous experiments.

Data were analyzed in the same manner described previously.

The acclimatization took place in a greenhouse with the following average temperatures $26^{\circ} \mathrm{C}$, during the day and $18^{\circ} \mathrm{C}$ during the night and with an average of relative humidity of $70-80 \%$ and constant ventilation. Seedlings were maintained under this humidity and sprayed with water every four days.

\section{Results}

\section{Time of in vitro culture in greenhouse conditions (pre-acclimatization)}

\section{Effect of pre-acclimatization on plant growth}

After seven months of the transplant, the highest growth of the aerial region of $L$. speciosa seedlings was observed for those pre-acclimitized in greenhouse conditions. The average increase of the new leaf length was $1.66 \mathrm{~cm} \pm 0.24$, followed by $1.29 \mathrm{~cm} \pm 0.23$ in seedlings that remained 25 days in pre-acclimatization; however no significant differences in this parameter between treatments were found. Significant differences were registered in width of the leaves $(\mathrm{F}=5.57$; gl $6 ; \mathrm{P}=0.000)$, in the length of the new psuedobulb $(\mathrm{F}=2.4 ; \mathrm{gl} 6 ; \mathrm{P}=0.032)$ and in the vigor $(\mathrm{F}=3.48 ; \mathrm{gl} 6 ; \mathrm{P}=0.003)$. The treatment of 20 days of pre-acclimatization was significantly higher than others (Fig. 2), also in this treatment the plants were more vigorous with healthy green leaves.

Significant differences among the treatments were not observed for length and width of the roots of the new pseudobulb. No significant differences in seedling survival among the treatments were detected.

\section{Effect of pre-acclimatization on stomata opening}

The initial observations (in June) revealed stomatal closure in the 0 treatment days of pre-acclimatization. In all treatments the majority of stomata are closed and few partially open. There were significant differences in the stomata opening during different times of day in all three pre-acclimatization treatments shown here: 0 days $(\mathrm{F}=6.505$, gl 2, $\mathrm{P}=0.002)$ (Fig. 3a,b,c), 20 days $(\mathrm{F}=12.871$, gl 2, $\mathrm{P}=0.000$ ) (Fig. 3d,e,f), and 30 days ( $\mathrm{F}=19.37, \mathrm{gl} 2$, $\mathrm{P}=0.000)($ Fig $3 \mathrm{~g}, \mathrm{~h}, \mathrm{i})$, revealing a tendency for stomata to open during the day. Moreover, significant differences in stomata opening are registered during different time of exposure at different hours of the day: 5:00 a.m. $(\mathrm{F}=25.441 \mathrm{gl} \mathrm{2}, \mathrm{P}=0.000)$ (Fig. 3a,d,g), 9:00 a.m. $(\mathrm{F}=27.149$, gl 2, $\mathrm{P}=0.000$ ) (Fig. 3b,e,h), and 2:00 p.m. $(\mathrm{F}=41.678, \mathrm{gl} 2, \mathrm{P}=0.000)$ (Fig. 3c,f,i). At 0 day pre-acclimatization treatment, stomata opening was significantly less frequent compared to the other treatments.

At the end of the experiment (September), three months after of culture in greenhouse conditions, any significant differences were detected at different hours of the day for the 0 and 20 day pre-acclimatization treatments. Nevertheless, there was a trend of increase in the percentage of the stomata opening or partially opened (Fig. 4a,b,c and Fig. 4d,e,f), during the day. In the 30 day treatment significant differences were registered at different times of the day $(\mathrm{F}=4.543, \mathrm{gl} 2, \mathrm{P}=0.011)$ (Fig 4g,h,i), with 
the highest (62\%) opening at 9:00 a.m. When comparing the treatments in each of the observation times, significant differences were found at 5:00 a.m. $(\mathrm{F}=6.010, \mathrm{gl} 2$, $\mathrm{P}=0.003)$, 9:00 a.m. $(\mathrm{F}=20.232$, gl $2, \mathrm{P}=0.000)$, and $2: 00$ p.m. $(\mathrm{F}=8.369, \mathrm{gl} 2, \mathrm{P}=0.000)$. For the 0 day treatment, stomata opening was significantly less frequent than in the other treatments at 9:00 a.m. and 2:00 p.m.

\section{Effect of different levels of MS nutrients previous to acclimatization}

The seedlings of L. speciosa cultivated in the treatment with $100 \%$ of MS nutrients recorded an increase in the length of the leaf of $1.3 \mathrm{~cm}( \pm 0.171)$, whereas the treatment lacking nutrients ( $0 \%$ of MS) the increase was of
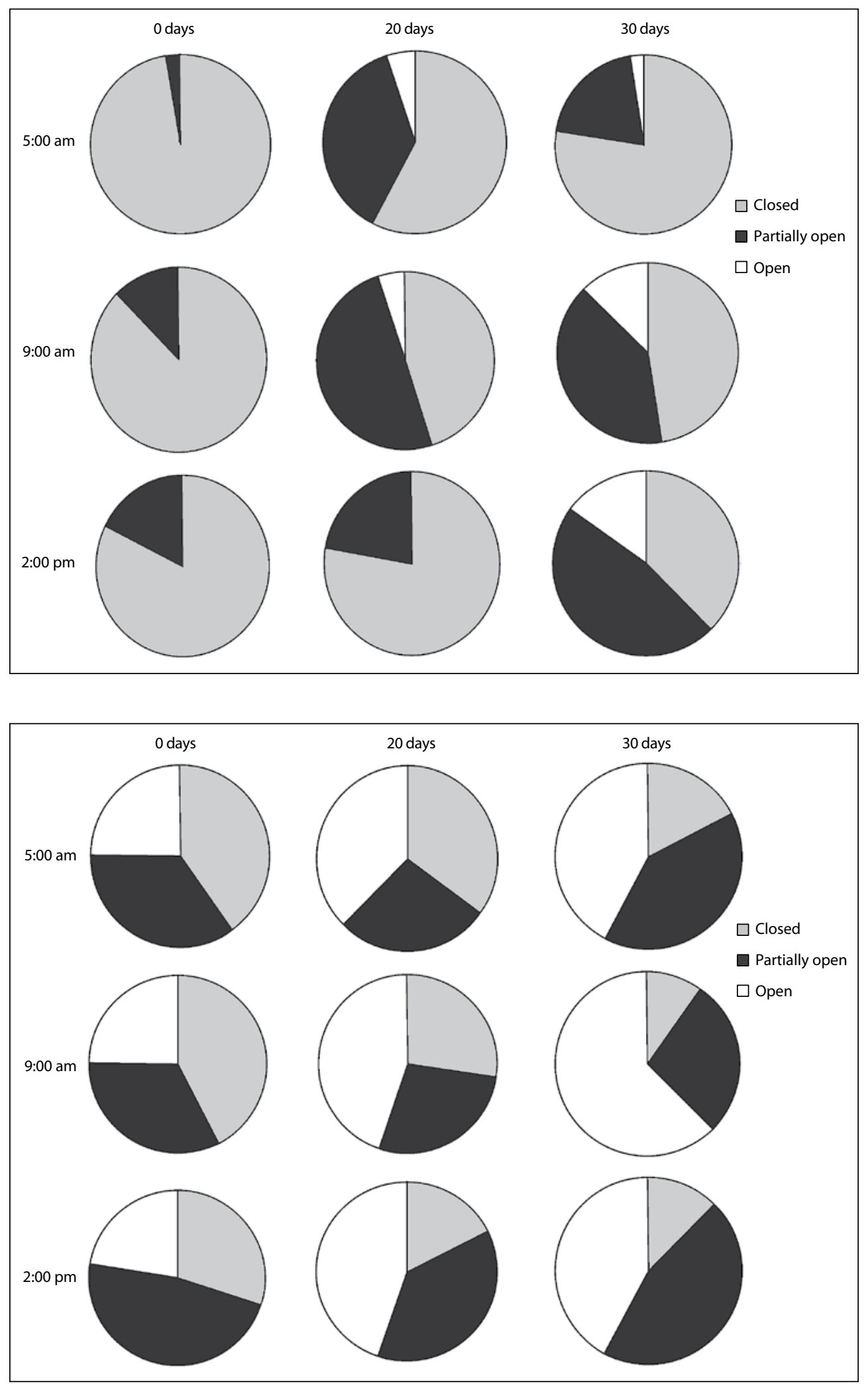

Fig. 3 Stomata opening of Laelia speciosa seedlings with different pre-acclimatization times: 0 days $(a, b, c$ at 5:00 a.m., 9:00 a.m., and 2:00 p.m. respectively), 20 days (d, e, fat 5:00 a.m. 9:00 a.m., and 2:00 p.m.), and 30 days $(g, h, i$ at 5:00 a.m., 9:00 a.m., and 2:00 p.m. respectively), at initial observations (June).

Fig. 4 Stomata opening of Laelia speciosa seedlings with different pre-acclimatization times: 0 days, $(a, b, c$ at 5:00 a.m., 9:00 a.m., and 2:00 p.m. respectively), 20 days (d, e, fat 5:00 a.m., 9:00 a.m., and 2:00 p.m.), and 30 days $(\mathrm{g}, \mathrm{h}, \mathrm{i}$ at 5:00 a.m. 9:00 a.m., and 2:00 p.m. respectively), after 3 months of transplanted (final observations). 


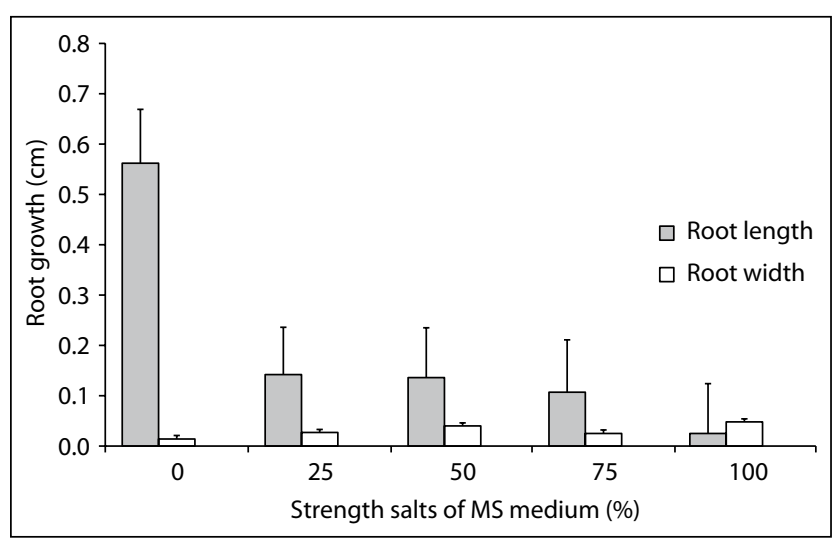

Fig. 5 Effect on root growth $(\mathrm{cm})$ of Laelia speciosa seedlings during acclimatization with different percentages of strength salts in MS medium.

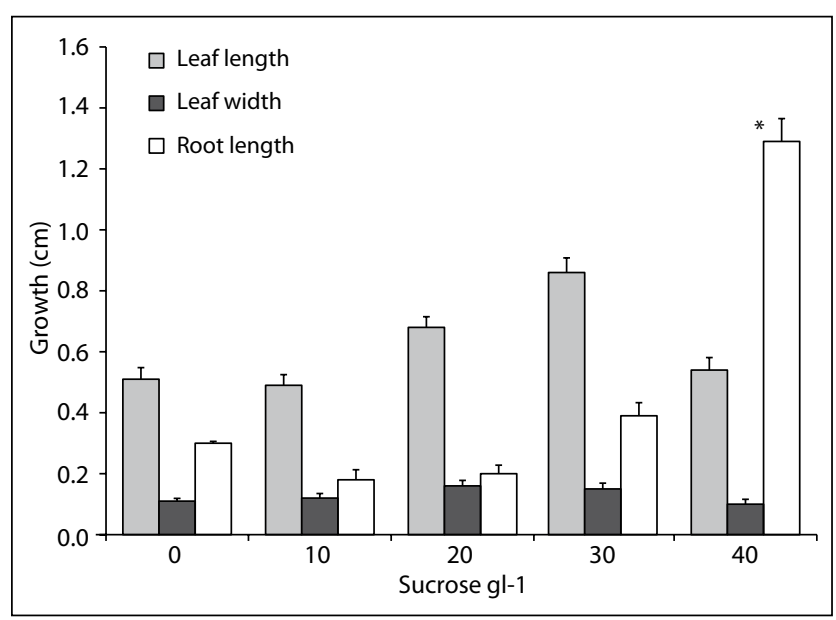

Fig. 6 Growth of seedlings of Laelia speciosa during acclimatization after cultured in vitro with different sucrose concentration in the MS medium.

$0.78 \mathrm{~cm}( \pm 0.187)$, however, no significant differences were observed. No significant differences were also not detected in the width or lenght of the leaf of the new pseudobulb either.

Seedlings cultivated in the $0 \%$ MS treatment developed significantly longer roots $(\mathrm{F}=3.96, \mathrm{gl} 4, \mathrm{P}=0.004)$ with an increase of $0.56 \mathrm{~cm}( \pm 0.23)$ (Fig. 5). The treatments applied did not show a significant increment in the width of the root. In this treatment, the plantlets showed a low vigor, because the plants were chlorotic or reddish, thin and flexible leaves. In contrast, the plantlets cultivated in treatment $100 \%$ MS, were vigorous with optimal growth. No significant differences were revealed in the survival of seedlings cultivated to different levels of MS nutrients, with high percentages of $97.5 \%$ to $100 \%$ recorded.

\section{Effect of sucrose concentration in MS medium previous to acclimatization}

The effect of sucrose concentration was determined in the acclimatization of $L$. speciosa plantlets, measuring growth of the aerial part and roots during greenhouse cultivation. The results of the growth of aerial part of seedlings did not present significant differences between treatments (different concentrations of sucrose; Fig. 6). However, there were significant differences in the length of the roots of these seedlings $(\mathrm{F}=3.96, \mathrm{gl} 4, \mathrm{P}=0.005)$. Seedlings cultivated on MS with $40 \mathrm{~g} / \mathrm{l}$ sucrose prior to transplantation displayed a significant increase in root length (Fig. 5). Plantlets also displayed more vigor using this treatment evident by high (97.5\%) survival after 60 days of being transplanted in the greenhouse.

\section{Discussion}

\section{Time of in vitro culture in greenhouse conditions (pre-acclimatization)}

Seedlings of $L$. speciosa with 20 days of pre-acclimatization registered the highest growth and vigor compared to those without it. Acclimatization of orchids and in vitro hardening has also been successful for other epiphytic orchids such as Arachnis labrosa and Cleisostoma racemiferum, in which the $1 / 10$ liquid MS basal medium was employed and subsequently replaced by an alternate substratum. Such plants were maintained under normal laboratory photoperiod and temperature conditions for three months and showed a significant increase on survival rate at ex vitro conditions (Deb and Imchen 2010). In the same way an in vitro hydroponic system for Cattleya tigrina increased survival and growth of ex vitro plants (Lopes da Silva et al. 2006).

In this study, we found that seedlings of L. speciosa without pre-acclimatization, after 30 days of being transplanted, did not present fully open stomata at any part of the day and just a small percentage of stomata were partially opened. These results agree with data reported by Roberts and Smith (1990), who reported that in vitro Chrysanthemum plantlets showed partially open stomata, and that rapid ex vitro transfer led to high mortality. Similarily, in vitro Malus pumila plantlets had low stomatal conductance (indicating stomata closed or slightly open) after transfer ex vitro culture (Díaz-Pérez et al. 1995). General plant literature has reported changes during acclimatization that include: development of cuticle, epicuticular waxes, and effective stomatal regulation of transpiration (Pospíšilová et al. 2007). Particularly, for orchids morphological and functional changes during acclimatization had been reported. For example in Cattleya jenmanii; leaves that developed during this process showed reversion of some abnormalities observed in vitro, in addition to an increase of stomata size (Torres et al. 2006). For Dendrobium hybrids, an increase of stomata size in acclimatizated plants in relation to in vitro micropropagated plants was also observed (Anita et al. 2000).

In this study, we provide evidence of functional changes in L. speciosa seedlings during acclimatization, by recording an increase in the percentage of open stomata 
over time for all pre-acclimatization treatments. Nevertheless, in the treatment without pre-acclimatization and on the 5th day of treatment, a significantly lower percentage of stomata were open compared to seedlings with a larger pre-acclimatization period. In those seedlings subjected to a 20 day period of pre-acclimatization, a higher percentage of open stomata were observed coupled with significantly improved growth and vigor compared to other treatments. We suggest that pre-acclimatization is an important factor in promoting stomatal functioning prior to transfer, resulting in seedlings that are more wellsuited to survival under greenhouse conditions.

\section{Effect of different levels of MS nutrients previous to acclimatization}

Prior to transplantation of plantlets, it has been suggested that a decrease in nutrient concentration within in vitro culture media can be used to obtain more vigorous roots and higher survival rates during acclimatization (Preece and Sutter 1991; Cusi, pers. comm.). Nevertheless, although $L$. speciosa had significantly larger roots in the treatment lacking nutrients, vigor of plantlets was low and leaves were reddish in color, thin, and less turgid compared to the treatment containing more nutrients. Thus, we advocate the use of a higher nutrient content prior to acclimatization.

No significant differences were detected in the survival of seedlings during acclimatization, possibly because the acclimatization used in the previously-developed method (Ávila-Díaz et al. 2009), and the use of a fungicide, favored survival of L. speciosa.

\section{Effect of sucrose concentration in MS medium previous to acclimatization}

Seedlings in the $40 \mathrm{~g}^{-1}$ of sucrose treatment yielded a significantly greater increment in root length (Fig. 6).

Serret et al. (2001) reported optimal growth in the acclimatization stage using high sucrose concentrations during the previous in vitro culture phase. The hardening of in vitro plantlets by decreasing the osmotic potential in the medium by the addition of sugars can ameliorate wilting of plants after transplantation, but very high concentrations of sucrose in the medium can slow development (Pospíšilová et al. 2007).

\section{Implications for conservation}

The in vitro propagation and acclimatization of L. speciosa and other orchids to produce plants of exceptional quality, is an alternative that might help by decreasing pressure on natural populations. In vitro propagated plants could also being used for re-introduction, but it is important to use a large quantity of seeds from as many capsules as possible from the local plants or from the closest population in order to maintain the natural genetic variation and structure (Ávila-Díaz and Oyama 2007).

Moreover, L. speciosa micropropagated plants that are kept under greenhouse conditions may be used as a source in Mexican religious art; thereby diminishing the impact on wild populations, promoting its sustainable management with a central issue for an orchid that has been used for centuries in many different ways.

\section{Conclusions}

This study provides an efficient protocol for in vitro propagation and acclimatization for the conservation of Laelia speciosa, via 20 days pre-acclimatization in greenhouse conditions coupled with high concentrations of nutriments and sucrose within the in vitro culture prior to its transplant.

This acclimatization L. speciosa work has great application possibilities for obtaining seedlings with high survival percentages and growth with the purpose of accomplish a sustainable management of this threatened species.

\section{Acknowledgements}

To Fondo Mexicano para la Conservación de la Naturaleza for the support given through "Manejo Sustentable de Laelia speciosa" proyect (A1-99/130), to the Coordinación de la Investigación Científica de la Universidad Michoacana de San Nicolás de Hidalgo for the support in the "Biología de la Conservación de Orquídeas Michoacanas" project. We also acknowledge Dr. Ken Oyama for his colaboration within the global proyect, to A. Valencia for their technical assistance and Landy Izquierdo for her help with English.

\section{REFERENCES}

Anita S, Priya L, Rajmohan K, Alex S (2000) Comparison of chlorophyll content, water loss, and anatomical features of leaves of the normal, in vitro cultured and, hardened Dendrobium hybrid plants. J Orchid Soc India 14: 41-46.

Ávila-Díaz I, Oyama K (2007) Conservation genetics of an endemic and endangered epiphytic Laelia speciosa (Orchidaceae). AM J Bot 94: 184-193.

Ávila-Díaz I, Oyama K, Gómez-Alonso C, Salgado-Garciglia R (2009) In vitro propagation of the endangered orchid Laelia speciosa. Plant Cell Tiss Organ Cult 99: 335-33.

Brainerd KE, Fuchigami LH (1981) Acclimatization of aseptically cultured apple plants to low relative humidity. J Am Soc Hort Sci 106: 515-518.

Deb CR, Imchen T (2010) An efficient In vitro hardening technique of tissue culture raised plants. Biotechnol 1-5.

Debergh PC, Zimmerman RH (1991) Micropropagation: technology and application. Kluwer Academic Publishers, Dordrecht, The Netherlands. 
Díaz LP, Namur JJ, Bollati SA, Antonio-Arce OE (2010) Acclimatization of Phalaenopsis and Cattleya obtained by micropropagation. Rev Colomb Biotecnol XII: 27-40.

Díaz-Pérez JC, Sutter EG, Shackel KA (1995) Acclimatization and subsequent gas exchange, water relations, survival and growth of microcultured apple plantlets after transplanting them in soil. Physiol Plant 95: 225-232.

Grout BWW (1975) Wax development on leaf surfaces of Brassica oleraceae var. currawong regenerated from meristem culture. Plant Sci Lett 5: 401-405.

Lee N, Wetzstein HY, Sommer HE (1988) Quantum flux density effects on the anatomy and surface morphology of in vitro and in vitro-developed sweetgum leaves. J Amer Soc Hort Sc 113: 167-171.

Lopes da Silva AL, Henz FET, Horbach MA, Walter JM (2006) Aclimatização de mudas de Cattleya tigrina A. Rich. Ex Beer (Orchidaceae) em sistema hidropônico. Cuaderno de Pesquisa Sér Bio 18: 129-139.

Murashige T, Skoog F (1962) A revised medium for rapid growth and bioassays with tobacco tissue cultures. Physiol Plant 15: 473-497.

Pospíšilová J, Synková H, Haisel D, Semorádová Š (2007) Acclimation of plantlets to ex vitro conditions: Effects of air humidity, irradiance, $\mathrm{CO}_{2}$ concentration and abscisic acid (a review). In: Santamaría JM, Desjardins Y (eds) Proc. IInd IS on Acclim and establt of micropropagated plants. Acta Hort 748: 29-36.

Preece JE, Sutter EG (1991) Aclimatization of micropropagated plants to the greenhouse and field. In: Debergh PC, Zimmerman
RH (eds) Micropropagation, Technology and Aplication. Kluwer Academic Publishers, Netherlands, pp 71-73.

Roberts AV, Smith EF (1990) The preparation in vitro of Crysanthemum for transplantion to soil. Protection of roots by cellulosa plugs. Plant Cell Tiss Organ Cult 21: 129-132.

Sarabia OME, Ávila-Díaz I, Gómez CA, Salgado-Garciglia R (2010) Callus growth and plant regeneration in Laelia speciosa (Orchidaceae). Lankesteriana 10: 13-18.

Seidel-Junior D, Augusto-Venturieri G (2011) Ex vitro acclimatization of Cattleya forbesii and Laelia purpurata seedlings in a selection of substrates. Acta Scient Agronomy, Maringá 33: 97-103.

Serret MD, Trillas MI, Araus JL (2001) The effect of in vitro culture conditions on the pattern of photoinhibition during acclimation of gardenia plantlets to ex vitro conditions. Photosynthetica 39: 67-73.

Sorace M, Tadeu FR, Yukari LY, Schnitzer JA, Assari LST (2007) Influence of auxin on acclimatization of Oncidium baueri (Orchidaceae). Semina: Ci Agrárias, Londrina 28: 195-200.

Suárez-Quijada I, Hernández-Altamirano M, Chávez-Ávila VM, Sandoval-Zapotitla E, Martínez-Palacios A (2007) Propagación in vitro y aclimatización de Euchile mariae (Ames) Withner (Orchidaceae). Lankesteriana 7: 388-393.

Torres J, Laskowski L, Sanabria ME (2006) Efecto del ambiente de desarrollo sobre la anatomía de la epidermis foliar de Cattleya jenmanii Rolfe. Bioagro 18: 93-99.

Wetzstein HY, Sommer HE (1983) Scanning electron microscopy of in vitro-cultured Liquidambar styraciflua plantlets during acclimatization. J Amer Soc Hort Sci 108: 475-480. 